\title{
The Problem and Response of School Sports Venues that Open to the Public under the National Strategy of the National Fitness
}

\author{
Guo Shian, Dai Yongguan \\ Jiangxi Normal University, Jiangxi, China
}

Keywords: School Sports Venues, National Strategy, National Fitness

\begin{abstract}
Mass sports is the chief component of sports, one of the basic segment of sports, the fundamentality of the construction of sports power, The Third Plenary Session of the 18th CPC Central Committee put forward to promote the modernization of national management system and management ability. The construction of sports powers need to promote the modernization of the national fitness system. The biggest bottleneck restricting the development of mass sports is the serious lack of public sports facilities. The national fitness rises to the national strategy, which brings new opportunities and new changes for deepening mass sports reform in all directions. The school sports venues that open to the public under the national strategy of the national fitness is the primary way to solve the lack of national fitness facilities, analyzing the problems of school sports venues open to the public in security, funds, management system and operation mode, etc by the method of interview, the method of literature. Make certain the service concept and realize the function of school sports venues mass sports service.; improve the management level and ensure the normal service of school sports venues, reinforce the various measures at the same time, and ensure the safety of the school sports venues mass sports service implementation, providing better theoretical guidance and sustainable school sports venues open mode for our country school sports venues open to the public preferably.
\end{abstract}

\section{Introduction}

The State Council issued the "National Fitness Program (2016 - 2020)" and pointed out: the implementation of national fitness program is an important national development strategy on June 23, 2016. In order to enhance people's physique and raise their health level as the basic goal to meet the growing population of diverse sports fitness needs as the starting point and the foothold. With the sustained development of the national political economy and society, the people's living standards continue to improve, the general awareness of mass sports fitness, and the number of participants in physical training has increased significantly. At the same time with the diversification of fitness needs and diversification of the development of sports facilities, the lack of contradiction in the supply of stadium facilities is more prominent. According to the sixth national sports venues census office to provide the data, China has a total of 169.46 million sports venues, including sports system management of sports venues 24,300 and Education system management of sports venues 66.05 million(institutions of higher learning have 49700, primary and secondary schools have 58.49 million, other education system units have 25,900). The number of sports venues in the education system accounts for $38.98 \%$ of the total number of sports venues in the country, and $89.3 \%$ of the education system is concentrated in primary and secondary schools. The State Sports General Administration and the Ministry of Education to develop National school sports venues to the community to implement the approach and other relevant policies and regulations, the country to carry out school sports venues open to the community pilot work. In 2008, the State Sports General Administration and the Ministry of Education issued Opinions of the Central Committee of the CPC and the State Council on strengthening juvenile sports and strengthening the physical condition of teenagers, and to promote the implementation of the second 
phase of the second phase of the National Fitness Program. The national school sports venues open to the public pilot work, and actively explore and establish the school sports venues open to the public an effective way and long-term mechanism. The Ministry of Education and National Department of Sport jointly issued the Opinions on advancing the opening of the school 's sports venues to the community, and actively alleviate the contradiction between the growing demand for sports and fitness for the young people and the masses and the lack of supply of sports venues, to promote the prosperity of the cause of the development of fitness. In the national fitness national strategy, the school's sports venues in a variety of forms to the community open to meet the needs of the public sports fitness. However, the current sports venues $38.98 \%$ of the school sports facilities to the community open rate is numbered. At present, China is facing the teaching properties of sports venues and social fitness requirements do not match, the school sports stadium facilities lack of resources, the use of efficiency is not high and schools, social needs between the contradiction between supply and demand. Faced with the teaching time and social opening time conflict, service operation profitability and public welfare is difficult to balance and the responsibility of the identification is difficult to distinguish and other grim situation. School sports venues open to the community is the school and sports authorities in common responsibility, but also an important area of scientific research researchers.

\section{The problems of school sports venues opening to society}

The government has promulgated a number of documents, such as the Sports Law stipulates that public sports facilities should be open to the public and be convenient for the masses to carry out sports activities in 1995. Zhejiang Provincial Government issued a document named Some Implementation Opinions on the Promotion of Openness of School Sports Facilities to the Public to the Provincial Sports Bureau and the Provincial Education Department, requiring that school sports facilities should be open to the public in batch as well as in phase and that things should be done in a more mature and open way in 2011. The government has in the National Fitness, Public Culture and Sports Facilities Ordinance, National Fitness Program and other laws and regulations require the relevant schools responsible for the community to open sports facilities. School sports venues after school time must be open to students, and take effective measures to strengthen security. Accelerate the school sports venues open to the community, and regularly open to the community. The policy on the opening of school sports venues has existed for more than 20 years. So what is the actual degree of openness? For this rule, one-third of the school's current attitude is positive, one-third is negative and one-third of the matter does not concern one personally. Education departments, Development and Reform Commission, tax department, Price department and other units did not joint signature, lack of lack of demand, good policy did not go to the implementation, so that the campus stadium door difficult to open.

Under the national fitness strategy school sports venues for the community is a good thing, but the school sports venues open after the occurrence of a variety of sports injuries accident is difficult to avoid, campus security risks brought by opening up affects all school leaders and managers of the heart. Security work, the responsibility is more important than the Taishan. Education commission on the assessment of the school security incident to implement a veto system, and security incidents directly affect the reputation of a school, the school has become a school sports venues open to the community is dilemma. Safety has become one of the difficulties of school sports venues opening to the public. School stadium to open the community to bring security risks: First, the school order will be chaotic, the school sports venues open, into the school sports venues of the social members of diverse, complex situation, and has greater uncertainty. The Exerciser could lead to an injury which may be in dispute at the venue, in the event of a conflict in the game, or deliberately provoke a fight. Second, the movement may be injured. Appropriate exercise can help to enhance physical fitness, to help the body get healthy, but because of everyone's health and physical capacity are not the same, so when the need to exercise according to their own circumstances to develop the correct exercise program. The stadiums who enter the stadium are not the same because of their age, occupation, sex, identity, physical fitness, functional level and athletic skills. In the absence of 
sports medical supervision, lack of sports technical guidance and exercise sports knowledge of the uneven. It will inevitably lead to a variety of injuries occurred, such as muscle strain, fracture or even broken and so on. Third, the school venues facilities lack of security. The use of age-old lack of maintenance of the stadium, the destruction of a serious lack of monitoring and maintenance of sports facilities and use of low quality does not meet the standard equipment. Stadium operators and staff do not perform their duties or perform improperly. The exerciser does not obey the correct guidance to violate the rules of the use of equipment, the blind use of sports equipment and so are the risk of personal injury accidents caused by exercise. School sports facilities to the community should be to ensure the safety of teachers and students and does not affect the school normal education and teaching order under the premise of implementation. But also to ensure that training groups, managers, school property safety, to ensure that sports facilities, health facilities, fire facilities, monitoring facilities intact.

The establishment of social coordination mechanism. School sports venues on the social needs of the community and the construction of two civilizations together. Now the new community with the venue to the community open and can design a reasonable mechanism. The community must be organized to the club and activities of the group to register, so that we can and the community docking, social development has a profound significance. However, the school is difficult to coordinate and implement these tasks. In the process of opening to the outside world, there are a series of problems such as the establishment of management mode or management system, the setting of management personnel, the suitable scope of open object, the rationality of opening time, the safety standard of open project and the standard of charging. To take what kind of management model, how the activities of personnel, exercise yard, activities of the order of unified and effective management. But now there is no ready answer, all around are groping or even wait and see attitude. The state is only designated around the open sports stadium, how to open, open the process of how the cost of the solution, the occurrence of injury accidents by whom a series of problems. Which led to many schools are not willing to open, so the lack of management measures is an important factor restricting the opening of sports venues.

\section{The Openness and Strategy of School Sports Venues to the Society}

To change the functions of the mass sports government is to change from the leadership and management to the opening of the school sports venues. The main work of the government is to study the problems, formulate policies, provide services and so on. The core issue is to correctly handle the relationship between government and society, government and market, and vigorously promote the socialization and marketization of mass sports. Every place should attach great importance to the school sports venues open work, establish a sound led by the education or sports sector. The relevant departments responsible for the division of labor and social forces involved in the opening of the venue coordination mechanism, take the initiative to fight for the support of the local government. Actively play the role of community, street management, research and development of local school sports venues open work plan or implementation of the program, and to implement. Collection of the school sports venues open implementation details, management system, open projects, management coordination group members and other information. Open the various cities need to establish by the local government, sports administrative departments, the education sector under the overall leadership, under the joint supervision of the relevant person in charge of joint research and opening up approach. Guidance and supervision of the work of the normal development of the formation of the principal directly responsible for the opening of the sports venues leading group. By the streets, communities (towns), public security and other departments responsible for the implementation of supervision responsibilities to ensure safety. And the school sports department of the Municipal Education Bureau, as well as of the Municipal Sports Bureau ,is responsible for the promotion, leadership , and co-ordination of the openness of the school stadiums in some pilot schools in coordination with all the neighborhood committee, all the community and so on. And regularly organize the exchange of sports venues open schools exchange of information, exchange of experiences, lessons learned, improve management, and better serve 
the broad masses of people. Effective management mechanism is an effective guarantee for the orderly conduct of school sports venues. Can take "two levels of government, three management" effective management model. We establish management system composed of street organization and school participation, and clarify division of duties and establish responsibility system. The streets are actively implementing matching bonuses, enhancing publicity, issuing activities cards to residents, encouraging residents and all kinds of clubs to use school resources to carry out activities. At the same time responsible for the community residents to promote scientific fitness knowledge, run a fitness knowledge lectures. And gradually promote the community residents fitness card and open day card. To limit the number and time of daily exercise to ensure that residents of the scientific fitness and school teaching work in a normal and orderly manner. Strengthen the daily inspection, urge the school to strengthen management, timely maintenance of vulnerable equipment. Regular visits to open schools to understand the situation. Analysis of the opening of the stadium in the course of possible problems, do a good job guiding and coordination.

Establish a sound organization. Each town (street) shall establish a management coordination group to participate in the town (street), the school office and the police station. It is responsible for coordinating the handling of the relevant issues in the opening activities of the sports venues. Perfect the responsibility of sharing the work of opening to the outside world, and clarify the functions and responsibilities of the relevant government departments in the opening to the outside world. The functional departments shall formulate the implementation plan. The opening of various sports venues to establish a standardized management system, including the management of the coordination group work system, the regular system, membership card management system or approach, members of the school activities code, activities, registration system, open log. In line with local conditions, the principle of effective management, the use of sports venues open school management, commission management or sports venues open school and community management, club membership management and other forms. Give full play to the role of community autonomy and mass self - management. During the opening hours, it is managed by volunteer and community volunteers in the school, and can be managed by a full-time administrator (the funds are shared by the participating communities, administrative villages or by the subsidized units). According to the on the school sports venues to the implementation of the views of the community to develop on the school sports venues opening up the implementation details, a clear school open conditions to complete the relevant legislation. The education sector may consider including the open work in the overall evaluation index system for school work and assess it on a regular basis. The school sports venues to the community open work into the comprehensive assessment of the school, into the demonstration school, key school assessment system. At the same time the school sports venues to the community open work into the civilized community and unit assessment. The school resources to the community open to the practice of innovation, the formation of advanced management model and the emergence of significant social benefits of the school to reward. This formed a virtuous circle.

All local education, sports departments to coordinate the local public security, medical and other departments, to strengthen the venues open security management and security. Schools to coordinate the surrounding communities and streets to develop specific venues open security implementation plan and emergency preparedness plan, the implementation of security risk prevention measures to strengthen the opening hours of security inspections, do the venue after the opening of the campus security work. School sports venues in the open to the community residents to provide public services, in addition to solve the facilities and facilities maintenance and management, fund raising and other issues, the sports venues in the process of opening up the security issue is also a problem can not be ignored, it to some extent About the enthusiasm of all levels of school venues open to the outside world. Therefore, the management at all levels should seriously consider all aspects of the opening of the venues, and take effective measures to avoid or even eliminate the security problems caused by the opening is not in place, to achieve the school sports venues open security mechanism. Which mainly include the following:

First, buy security insurance. In the school sports venues in the opening of the introduction of 
insurance, an effective means of security, is bound to better solve the opening process of security issues. Security insurance can be divided into two parts, part of the school sports facilities for the insurance, and the other part of the residents involved in the exercise of personal insurance. Through the purchase of security insurance, can effectively reduce the risk, so that the role of school sports venues to maximize. Both the teaching and open use, but also a good way to avoid the sudden security incidents caused by the dispute.

Second, the implementation of security system. Safety and participation of school sports venues how to protect the safety of residents is an important issue that restricts the opening of school sports venues. The solution of this problem requires multiple efforts. In addition to the introduction of the insurance system, but also need to have the relevant security system. Sports venues teaching area and open area to be clearly marked, if necessary, the two for a certain isolation. For those who come to participate in the exercise of the residents, the community or the relevant management departments should be registered for the record, and the issuance of relevant documents. Voucher access to schools and so on.

Third, to teach safety knowledge. In addition to the establishment of insurance means and the implementation of relevant systems, in the school sports venues in the process of opening up, but also to strengthen the safety of residents of education, from the ideological emphasis on security issues.For example, the school assigns specialized social sports instructors to educate residents who come to secondary schools for physical education. To explain the use of the relevant sports equipment and the correct way of exercise, as well as some common exercise injury treatment, so that residents participate in the exercise of correct and effective physical exercise and equipment use knowledge, to avoid unnecessary accidents.

Local education departments should increase the school venues facilities construction and opening up investment, and constantly improve the school sports venues facilities conditions. All local sports departments should be based on the actual situation, arrange the necessary funds to support the school sports venues open to the daily operation and facilities and equipment maintenance. Can use the lottery to raise the subsidy to open schools, arrange a certain percentage of funds as a venue for the opening of social sports instructor funding. Open venues school fees charged in strict accordance with the financial system for standardized management, mainly for subsidies to facilities operations. To implement self-management, but also to a qualified third-party management operations. This can be marketed to reduce school management costs. But the market is conducive to harm, the key is to do a good job managing the main responsibility to implement the basic protection. Open sports facilities can be implemented free of charge system. Free system requires the national sports authorities to increase the cost of this school to the corresponding subsidies, the two sides to start a different cooperation. In order to effectively use the school's sports facilities, improve the utilization of these sports facilities. The Government set up a special sports fitness institutions, the school's sports facilities to manage these are also a good way. At the same time in order to ensure the continued operation of these institutions, it is recommended to the school's indoor venues to the agency management, these indoor venues open to charge. Fees charged in addition to maintaining the normal operation of the organization, but also can give the school a certain compensation.

\section{Conclusion}

To develop the mass sports development plan, we must pay more attention to the speed shift of the revolutionary and public response model, and the opening of schools, stadiums and stadiums is not accomplished overnight. After all, many sports venues built in the relatively "closed" campus. Management, security, material consumption are faced with a series of problems. To solve the school sports venues for social open is a systematic project. In the process of opening up, we should fully mobilize and play the leading role of all levels of government, the formation of government-led, social concern, the relevant departments responsible for the division of work. Establish and improve the operation and protection policies for opening to the outside world, and ensure the effectiveness of school funds and effectively improve the school's enthusiasm. Only in 
this way can we ensure the normal teaching order and teaching environment in the process of opening the school so that the school sports venues can "live" and achieve the harmony of the two.

\section{References}

[1] Xu J. 2014. Research on the sports stadiums opening performance evaluation index system of primary and high schools in part districts of Shanghai[D]. Shanghai Institute of Physical Education.

[2] Chen GX, Zhang CY et al., 2013. Obstacles and optimization strategy of school sports venues opening to the public from the perspective of public service[J]. Journal of Shenyang Sport University. 2013,(01):58-61.

[3] Liu X, Liu J, Hu YY et al., 2011. The comprehensive analysis of policies and running pattern on public utility of sports facility in elementary and middle schools. [J]. Journal of Xi'an Physical Education University, 2011, (05): 530-533+554.

[4] Tan ZQ.2010. Legal basis for injury accident processing in public services at school sports venues. [J]. Journal of Beijing Sport University, 2010, (02): 35-37.

[5] Chen LH, Tan WL.2009. Research on the effective operation mechanism of how school sports venues should be open to the public. [J]. Journal of Chengdu Sport University, 2009, (03): 89-91.

[6] Xin SS, Chen LH.2007. Present situation and counter measures of opening to community of school gymnasium. [J]. Journal of Xi'an Physical Education University, 2007, (06): 37-39. 